\title{
Simboli i ceremonije - perspektive u proučavanju srednjovjekovlja
}

\author{
Pregledni rad \\ Review article \\ UDK 930.85:<003:394>(497.5)“04/14“
}

U članku se ocrtava proučavanje simbola iceremonija u povijesti srednjovjekovlja. Predstavljaju se dva najvažnija, njemačka, autora u dvadesetom stoljeću, Percy Ernst Schramm i Ernst Hartwig Kantorowicz, čiji se radovi smatraju pionirskima za proučavanje simboličnog u historiografiji srednjega vijeka. U manjoj mjeri za to je zaslužan i Francuz Marc Bloch. Zatim se dotiče primjera iz hrvatske historiografije, gdje je dosad najveći doprinos dao Igor Fisković. Na temelju dvaju primjera - vladarskih pogreba i ambicija grofova Celjskih - pojašnjavaju se spoznajne mogućnosti izučavanja simbolike za razumijevanje društvenopolitičkih procesa u prošlosti.

Ključne riječi: simboli i ceremonije, P. E. Schramm, E. H. Kantorowicz, Marc Bloch, hrvatsko srednjovjekovlje

$S^{i}$ imboli i ceremonije oduvijek su bili bitnim čimbenikom ljudskoga društva te se nalaze posvuda u našem okruženju. Državni i vjerski simboli, zastave, grbovi, pečati, značke, lente i odlikovanja, samo su neki od znakova i simbola s kojima se stalno susrećemo u svakodnevnom životu i pomoću kojih kategoriziramo svijet oko sebe. Nadalje, čitav život sudjelujemo u ceremonijama koje nagovješćuju ili svjedoče o našem prijelazu iz jednog životnog stadija u drugi. Krštenje, pričest, promocija, vjenčanje i pogreb samo su neke od brojnih s kojima se većina ljudi susreće u svome životu, kao sudionici ili svjedoci. Aristotel je rekao: „Onaj tko ne može živjeti u društvu ili za tim nema potrebe jer je dovoljan sam sebi, mora biti zvijer ili bog: on nije dijelom države“. Ujedno je tvrdio kako je „društveni instinkt prirodno ugrađen u čovjeka" (http://www.fordham.edu/halsall/ancient/Aristotle-politicspolis.asp). Drugim riječima, čovjek prirodno teži svrstavanju u hijerarhiju, što zbog podjele poslova prema Durkheimu (Durkheim 1972), što kao posljedica evolucije položaja vođe u društvu koji putem prestiža inspirira i utječe na svoje sljedbenike (McNamarra et al. 2007). Američki pravni povjesničar William lan Miller u svom je dugotrajnom proučavanju rituala mirenja, časti, ponosa i srama na primjeru srednjovjekovnih islandskih saga ovako sažeo političko i društveno djelovanje u tadašnjem društvu: „Čast pojedinca bila je krhka i podložna nasilju; njeno zdravlje bilo je strogo nadzirano putem osjećaja srama osobe i njene istančane sposobnosti procjene zavide li joj drugi više nego li ona njima“ (Miller 1997, 144). Miller je time iznio opažanje koje su potvrdila i suvremena psihološka istraživanja - da među ljudima postoji urođeni mehanizam ponosa i srama koji služi opažanju, procjenjivanju i određivanju vlastita položaja u hijerarhiji (Tracy et al. 2008). I u našem modernom društvu naoko nevidljivi 
čimbenici poput srama ili strahopoštovanja uvelike utječu na naše ponašanje u društvu. U predmoderno doba, a poglavito u srednjemu vijeku u kojem je društvena hijerarhija imala i službenu dogmatsku podlogu - sa zemaljskim kraljevstvom kao odrazom onog nebeskog nepisano i neizrečeno često je imalo prvorazrednu važnost.

\section{Vladarska simbolika}

Institucija vladara u srednjovjekovnom svijetu u potpunosti je bila prožeta simboličnim i ceremonijalnim kao svojim neizostavnim odrednicama. Kraljevi među starim Germanima bili su, prema Tacitu, birani, a pretpostavlja se da su vršili i svećeničke dužnosti, iako novija historiografija dovodi u pitanje bilo kakve zaključke o germanskim kraljevima prije njihova dolaska na teritorij Rimskog Carstva (Canning 1996, 16). Ne osporava se, međutim, činjenica da je, od prihvaćanja kršćanstva i rimskih tradicija, kraljevstvo u srednjem vijeku legitimirano milošću Božjom (Dei gracia), koja postaje sastavni element vladarske propagande i neizostavnim dijelom intitulacija u kraljevskim ispravama, što možemo pratiti na dokumentima franačkih careva, ali ih vidimo i, primjerice, $u$ ispravama hrvatskih narodnih vladara (Brković 1992). Osim ovih verbalnih komponenti, kult vladareve posebnosti izražavao se ponajprije u materijalnim oznakama koje i danas evociraju asocijacije na kraljevske i carske časti: kruna, žezlo, jabuka i mač. Historiografija devetnaestoga stoljeća, usmjerena na pozitivističko i romantičarsko prizivanje i opisivanje prošlosti, nije se pobliže bavila fizičkim i metafizičkim simbolima koji su služili legitimaciji i afirmaciji kraljevske moći. Tri su povjesničara dvadesetoga stoljeća postavila temelje novome pogledu na ovu problematiku: Percy Ernst Schramm, Ernst Hartwig Kantorowicz i, u nešto manjoj mjeri Mark Bloch.

Percy Ernst Schramm (1894-1970) jedan je od najznačajnijih njemačkih medijevista dvadesetoga stoljeća i prvi koji se sustavno i temeljito okrenuo izučavanju srednjovjekovnog političkog simbolizma, rituala i ceremonije te ideologije i vladarske propagande srednjovjekovne države. Schramm je u svojem monumentalnom djelu Die deutschen Kaiser und Könige in Bildern ihrer Zeit, 751-1190 (1928.) upotrijebio ikonografiju srednjovjekovnih vladara kao i ostale simbole autoriteta - poput pečata, grbova ili arhitekture - za analizu naravi vlasti uopće (Bak 1995; Thimme 2006). lako je Schrammov pristup naišao na kritiku u novijoj historiografiji, ne može se osporiti izvanredan doprinos njegovog marljivog sakupljanja ikonografskog izvornog materijala, kao i interpretacija koje su udarile pečat i tradicionalnoj povijesti, ali i povijesti umjetnosti (Warner 1999). Njegovo drugo i najznačajnije djelo u tri toma, Herrschaftszeichen und Staatssymbolik: Beiträge zu ihrer Geschichte vom dritten bis zum sechzehnten Jahrhundert (1954-1978) (Schramm 1954-1978) talijanski je filozof Giorgio Agamben nazvao „ogromnom pjesmom posvećenom znakovima moći” (Agamben 2011, 178) što ono uistinu i jest, budući da je na jednom mjestu skupljen gotovo čitav poznati ikonografski opus srednjovjekovnih franačkih i njemačkih vladara putem kojih je Schramm predstavio svojevrsnu mitologiju o vladarima u produkciji njihovog vlastitog propagandnog pogona (Schramm 1968). lako je njegov pristup bio usmjeren gotovo isključivo na njemačke vladare i njihove franačke prethodnike, Schrammov je pristup "otvorio nove pravce razumijevanja kraljevske samoreprezentacije i ideologije" (Althoff et al. 2002, 4). Zaprepašćujuća veličina njegova opusa, bez obzira na njegovu teritorijalnu ograničenost, djelovala je donekle i obeshrabrujuće na sljedeću generaciju povjesničara. Prema riječima Gerda Althoffa koji se u posljednja dva desetljeća posvetio problemima simbolične komunikacije, Schrammove pionirske studije navele su povjesničare na zaključak da više „nema potrebe za daljnjim istraživanjima gesti, znakova i rituala srednjovjekovnog političkog života“ (Althoff 1990, 21, bilješka 44). 
Drugi velikan srednjovjekovne simbolike je Ernst Hartwig Kantorowitz (1895-1963) koji je, poput Schramma, studirao u Heidelbergu kod dvojice tada najznačajnijih medijevista njemačke Geistesgeschichte, Karla Hampea (1869-1936) i Friedricha Baethgena (18901972). Norman Cantor je za njega i Schramma upotrijebio naziv "Naci blizanci“, budući da su obojica imali bliske veze s nacizmom (Cantor 1991). Schramm je bio službeni povjesničar njemačkog Glavnog stožera, zbog čega je svjedočio na suđenjima u Nürnbergu, a Kantorowicz je kao pruski časnik služio u Prvom svjetskom ratu, a zatim i kao pripadnik desne milicije sudjelovao u gušenju Poljskog ustanka (1918-19) i Ustanka spartakovaca u Berlinu. Unatoč svome židovskom podrijetlu bio je Goeringov prijatelj te je na naslovnici svoga, za nacističku ideologiju, vrlo utjecajnog djela o Fridriku II., upotrijebio svastiku. Njegovo veličanje njemačke nacionalističke ideje išlo je do te mjere da je uzvik „Ein Reich, Ein Volk, Ein Führer“ usporedio s Barbarossinim „Unus Deus, unus Papa, unus imperator“ (Boureau 2001, 5). U konačnici ga ni Goeringovo prijateljstvo niti njegova pisma Ministarstvu znanosti u kojima je branio svoju privrženost Reichu usprkos protužidovskoj politici, nisu mogli očuvati na katedri u Frankfurtu te je 1933. bio prisiljen dati ostavku i napustiti zemlju (Friedlander 2009, 55). Ironijom sudbine, Goebbels je dopustio reprint njegove knjige o Fridriku II. 1936., kada je Kantorowicz već bio u egzilu u Londonu koji je, zatim, 1939. zamijenio Sjedinjenim Američkim Državama (Kantorowicz 1936). Na Sveučilištu Berkeley u Kaliforniji se njegov svjetonazor, čini se, potpuno promijenio te je od desničara postao humanistom i odbio položiti obaveznu protukomunističku zakletvu, zbog čega je morao napustiti Berkeley i prijeći na Princeton (Boureau 2001, 6). Tamo je objavio i svoje najpoznatije djelo koje Princeton i danas smatra jednim od svojih najboljih publikacija, The King's Two Bodies (Kantorowicz 1957). Definirana kao studija o srednjovjekovnoj političkoj teologiji, knjiga detaljno razrađuje teoriju koju je Bernhard Jussen sažeo na sljedeći način: Kantorowicz je detektirao teoriju ili postavku o dva kraljeva tijela, fizičkom koje je smrtno, i političkom koje je utjelovljeno u kruni kao sukcesiji vladara te, samim time, nikada ne umire. Ta je teorija (ili načelo) „perfektno formulirana u tudorskoj Engleskoj i perfektno ritualno izvođena u ranonovovjekovnoj Francuskoj". Kantorowicz je novovjekovnu primjenu teorije izveo iz ranijih otonskih i karolinških predložaka, odnosno, korijene joj je našao u samim počecima srednjovjekovlja (Jussen 2009). Kantorowiczeva teorija naišla je na brojne kritike: zamjeralo mu se manjkavo tumačenje izvora, ali i prevelika simplifikacija ranosrednjovjekovnog političkog sustava, zbog čega je donekle napuštena osamdesetih godina dvadesetog stoljeća (Garipzanov 2008, 5-6). Međutim, kao što je ustvrdio i Jussen, unatoč svim nedostacima njegov je pionirski rad „utabao nove staze“ te postavio temelje za modernu konceptualnu historiju (Jussen 2009, 115). Nadalje, i na samom polju kraljevske simbolike postoje nastavljači njegova djela, na čelu s firentinskim povjesničarom Sergiom Bertellijem, čija je knjiga I/ corpo del re: sacralità del potere nell'Europa medievale e moderna (Bertelli 2001) svojevrsni duhovni nasljednik Kantorowiczeva magnum opusa (Bertelli 2001).

Uz spomenuta dva velikana istraživanja simbola i rituala u srednjem vijeku, svakako treba još spomenuti i jednog od utemeljitelja francuske škole Annales - Marca Blocha, koji je svoj doprinos ovome polju dao knjigom Les rois thaumaturges: étude sur le caractère surnaturel attribué à la puissance royale particulièrement en France et en Angleterre, objavljenom 1924. (Fink 1989). Dok su Schramm i Kantorowicz kraljevsku simboliku i rituale postavili u središte svog interesa kao predmet samog istraživanja, Bloch je - iako je tema njegove knjige bila kraljev iscjeliteljski dodir i njegova propagandna funkcija u komparativnom kontekstu - zapravo provodio antropološko istraživanje u srednjovjekovnom kontekstu, što je postala i odlika francuske škole Annales (Leeuwen 2006). Bloch je, međutim, napustio daljnji rad na ovoj tematici, vjerojatno zbog hladne recepcije njegove knjige te se posvetio 
proučavanju feudalnog društva i objavio istoimenu knjigu s kojom se i proslavio. Le rois thaumaturges je, ipak, u velikoj mjeri očuvala svoj značaj do današnjih dana (www.h-net. org/reviews/showrev.php?id=4706). lako je izučavanje simbola i ceremonija s naglaskom na vladajuće slojeve, ostalo ponajprije temom njemačke historiografije, Blochov i Le Goffov doprinos (o simboličnom ritualu vazaliteta) pokazao je da ta tematika nije ograničena samo na povjesničare proizašle iz njemačke historiografije (Le Goff 1997).

\section{Simboli i ceremonije u hrvatskoj historiografiji}

Hrvatska historiografija se simbola doticala ponajprije s aspekta klasičnih pomoćnih znanosti, heraldike, sfragistike i veksilologije, koje su kod nas cijenjene i uživaju tradiciju koja seže daleko u prošlost, a sami počeci mogu se datirati na početak osamnaestoga stoljeća i rad Pavla Rittera Vitezovića, Stematografija ili opis, objašnjenje i rekonstrukcija ilirskih grbova (Stemmatographia sive Armorum Illyricorum delineatio, descriptio et restitutio). Od njegova pionirskog rada za hrvatsku heraldiku, preko temeljnog udžbenika Bartola Zmajića Heraldika, sfragistika, genealogija, veksilologija do novijih izdanja poput Hrvatski grb Marijana Grakalića, riječ je ponajprije o normativno-deskriptivnim djelima kojima je osnovni cilj utvrditi pravila grboslovlja i srodnih disciplina te opisati postojeći korpus simbola i zakonitosti njihove upotrebe i kombiniranja njihovih različitih sastavnih dijelova (Galović et al. 2008). Jedini znanstvenik koji se, na prijelazu iz dvadesetog u dvadeset i prvo stoljeće, simbolikom u hrvatskom srednjovjekovlju bavio u duhu Schrammova nasljedstva je povjesničar umjetnosti Igor Fisković, koji je problemu identiteta vladarskog lika na reljefu u splitskoj krstionici u knjizi Reljef Petra Krešimira IV. pristupio upravo pomoću pomne i iscrpne ikonografske analize uz obilje komparativnog materijala suvremene zapadnoeuropske provenijencije (Fisković 2002). Fiskovićeva opsežna rasprava nije pružila definitivan i neosporan odgovor na pitanje je li na reljefu prikazan Zvonimir ili Petar Krešimir IV., što vidimo u novijim radovima Tomislava Marasovića i Ive Babića, koji nude drugačija tumačenja (Babić 2010; Marasović 2010). Ipak, njegova je zasluga, poput Schrammove - čije su tvrdnje isto dovedene u pitanje od strane moderne historiografije - u tome što je "probio led“ u hrvatskoj historiografiji te potaknuo na propitivanje prošlosti sa stajališta ikonografije i simbolike što se vidi i u Babićevom radu koji svoja tumačenja identiteta vladarskog lika nudi prema Fiskovićevom receptu. ${ }^{1}$ Kada će i hoće li uopće biti moguće konačno riješiti pitanje identiteta vladara na reljefu u splitskoj krstionici u ovome je slučaju manje važno od njegova doprinosa za proučavanje simbolike u hrvatskoj historiografiji.

U najnovije vrijeme mlada je riječka medijevistica Kosana Jovanović objavila knjigu pod naslovom Two Funerals and "Two Bodies" of King Richard II. u kojem je, kao Kantorowiczeva sljedbenica, obradila smjenu i prijenos političke moći kroz osobu kralja u 14. i 15. stoljeću u Engleskoj (Jovanović 2010). lako i tematski i jezično rad Kosane Jovanović pripada više engleskoj nego hrvatskoj historiografiji - iako je i na hrvatskome objavila zanimljivu studiju o kraljevskim efigijama kao posudama za transfer kraljevske moći s umrlog vladara na njegova nasljednika - za očekivati je i nadati se da će autorica dosad stečena znanja primijeniti i na temama iz hrvatske povijesti (Jovanović 2013).

Babić nudi mogućnost da je ležeći lik Petar Črnjina koji je pred kraljem Zvonimirom i kraljem Slavcem vodio niz sporova. lako ni njegova argumentacija nije ništa uvjerljivija od Fiskovićeve, pohvalno je što diskusija otvara pravce razmišljanja koji su dosad bili nepoznati u hrvatskoj historiografiji. 


\section{Primjena simbola i rituala na teme iz hrvatske povijesti}

U zaključku ovoga razmatranja dotaknut ćemo se dva primjera iz kasnoga srednjega vijeka koji ilustriraju kako nam simboli i rituali mogu pomoći u boljem razumijevanju naše srednjovjekovne prošlosti - pogreba hrvatsko-ugarskih vladara i uspona grofova Celjskih.

Na području Hrvatsko-Ugarskog Kraljevstva, širenje teorije o dva kraljeva tijela može se lako i jasno pratiti preko Anžuvinaca i njihovih pogrebnih ceremonija. Francuski pogrebni ceremonijal već se u razvijenom srednjem vijeku odvijao u skladu s teorijom o dva kraljeva tijela. Dolazak Anžuvinaca na hrvatsko-ugarsko prijestolje označio je i brojne novitete na dvoru. Jedno od njih bilo je širenje francuske viteške kulture na zemlje Krune sv. Stjepana. Dok su ugarski magnati već u prethodnom stoljeću počeli njegovati pravila i običaje viteškog života, niže su plemstvo takve inovacije zaobišle. Karlo Robert se upravo na njih oslanjao u borbi protiv magnata te je koristio razne metode promocije viteštva među njima kako bi ih čvršće vezao uz prijestolje (Engel 2005, 145-147). Dodjeljivao im je grbove, organizirao turnire i održavao curiu militaris kao svojevrsni dvor časti, a osnovao je i Red sv. Jurja, koji je nove vitezove trebao držati na okupu sponama časti i odanosti. Viteški red nastavio je poticati i njegov sin i nasljednik, Ludovik Veliki. Stvaranje raskošnog dvora i promocija viteštva bile su simbolične metode jačanja kraljevske vlasti naspram moćnih magnata, pri čemu je strahopoštovanje prema kraljevskom autoritetu trebalo zatomiti bilo kakve pobunjeničke ideje (Boulton 1987, 27-45).

Francuski utjecaj očitovao se i na primjeru vladarskih pogreba. Poljski povjesničar Aleksander Gieysztor analizirao je gestikulaciju u krunidbenom ceremonijalu srednjovjekovne Poljske. Pritom se osvrnuo na pogrebni ceremonijal koji je prethodio samoj krunidbi te ustvrdio da je od pogreba Kazimira Velikog 1370., koji je organizirao njegov nasljednik Ludovik Anžuvinac u ceremonijal pridodan element viteza na konju koji bi ujahao u crkvu za vrijeme pogreba te se teatralno i uz pompu srušio na tlo, polomivši svoje koplje dok su istovremeno lomljeni pečati preminuloga. "Smrt" viteza i uništavanje njegovih identifikacijskih oznaka trebali su dočarati trenutak fizičke smrti vladara, ali ne i smrti njegova politička tijela koje je bilo vječno što su u šesnaestom stoljeću jasno dočarali i frazom „osoba pańska umiera, korona nie umiera" (Gieysztor 1989). Vitez koji je predstavljao umrloga bio je sastavni dio francuskog ceremonijala, a u Ugarsku je uveden prilikom pogreba Karla Roberta (Petneki 1997). Zatim je korišten i na pogrebu Karla IV. 1378. i Ladislava Postumnog 1457. (Bláhova 1997). Pomoću teorije o dva kraljeva tijela možemo jasno pratiti put kojim je političkoteološka teorija o svetosti i vječnosti kraljevske institucije, posredstvom Anžuvinaca i Luksemburgovaca, postala sastavnim dijelom vladarske propagande i u našim krajevima.

Grofovi Celjski zahvalna su tema sa stajališta simbolike, budući da su vješto koristili simbolički jezik kao propagandno sredstvo u obrani svojeg novostečenog položaja kneževa Svetog Rimskog Carstva, što su im Habsburgovci na čelu s Fridrikom III. osporavali radi zaštite vlastitih teritorijalnih ambicija (Kurelić 2006). Sukob oko priznavanja kneževske titule reflektirao se i na polju sfragistike te su Celjski četrdesetih godina petnaestoga stoljeća proizveli tri značajna kneževska pečata kojima su projicirali svoje težnje i ambicije. Među elementima njihova pečata bio je i tadašnji hrvatski, a danas dalmatinski grb s tri okrunjene lavlje glave na plavoj pozadini, smješten na heraldičku desnu stranu, čime su pokazali da im je Zagorje - posjed koji je, pored Celja i Ortenburga, tvorio treći dio njihove intitulacije - po važnosti odmah iza njihovog matičnog posjeda (Kurelić 2006a). Razvijeni osjećaj za visoku dvorsku politiku i ceremonije među posljednjim pripadnicima Celjskih utjecao je i na njihove rođake, Frankopane, koji se u pratnji Ulrika II. nalaze i na Reichstagu u Nürnbergu, a djelomično su zaslužni i za prodor zapadnih titula na rubna područja Hrvatsko-Ugarskog 
Kraljevstva. Dinastička ambicija Hermana II. proizvela je 1433. i jedan poseban pečat na kojem je naglasio svoj položaj slavonskoga bana, a koji podsjeća na slične pečate Šubića s početka četrnaestog stoljeća (Antoljak 1972, 21-22). Da je taj pečat bio namijenjen vladarskoj propagandi na teritoriju Hrvatsko-Ugarskoga Kraljevstva, vidljivo je i po tome što je celjski štit okružen zmajevima, što je očit znak Hermanove pripadnosti Zmajskom viteškom redu, koji je osnovao Sigismund 1408. godine. Za razumijevanje povijesti Celjskih i njihovog političkog i društvenog djelovanja u hrvatskim zemljama, simbolika i rituali - od viteškog hodočašća Ulrika II., preko krunidbe Ladislava Postumnog pa sve do značenjima nabijenog pogreba Ulrika II. u Celju - predstavljaju neizostavan aspekt proučavanja kako bi se njihova uloga za hrvatsku historiografiju mogla pravilno vrednovati.

\section{Umjesto zaključka}

Svaka generacija ima svoju historiografiju koja ponekad nastaje preuzimanjem trendova iz susjednih historiografija, a ponekad potpuno autonomno. Dok je francuska škola Annales naišla na poklonike u Hrvatskoj, istraživanje simbolike i rituala još je u povojima, iako se pokušaji u primjeni metodologija inspiriranih Schammom i Kantorowiczem naziru među suvremenim hrvatskim povjesničarima. Autor ovih redaka nada se da će ovaj kratki osvrt na početke istraživanja srednjovjekovne simbolike motivirati i inspirirati znanstvenike i studente da u svojim istraživanjima promišljaju i o simboličnim i propagandnim stranama povijesti koje su, doduše, teže za dokučiti, ali koje su u velikoj mjeri mogle utjecati na ponašanje povijesnih aktera, a to donekle čine i danas.

\section{POPIS LITERATURE}

http://www.fordham.edu/halsall/ancient/Aristotle-politics-polis.asp (28. veljače 2014.)

www.h-net.org/reviews/showrev.php?id $=4706$ (28. veljače 2014.)

\section{AGAMBEN 2011}

Giorgio Agamben, The Kingdom and the Glory: For a Theological Genealogy of Economy and Government (Homo Sacer II, 2), prev. Lorenzo Chiesa i Matteo Mandarini, Stanford 2011.

\section{ALTHOFF 1990}

Gerd Althoff, Verwandte, Freunde und Getreue: zum politischen Stellenwert der Gruppenbindungen im frühen Mittelalter, Darmstadt 1990.

\section{ALTHOFF ET AL. 2002}

Gerd Althoff, Johannes Fried i Patrick J. Geary, "Introduction“, u:, Medieval Concepts of the Past: Ritual, Memory, Historiography, Cambridge 2002., 1-17.

\section{ANTOLJAK 1972}

Stjepan Antoljak, „Ban Pavao Bribirski Croatorum dominus", Radovi Instituta JAZU u Zadru 19, Zadar 1972., 5-62.

\section{BABIĆ 2010}

Ivo Babić, „O reljefu s prikazom kralja iz Splitske krstionice", Archaeologia Adriatica 4, Zadar 2010., 203-215.

\section{BAK 1995}

János Bak, „Percy Ernst Schramm“, u: Medieval Scholarship: Biographical Studies on the Formation of the Discipline, vol. 1, History, (ur. Helen Damico i Joseph B. Zavadil), New York 1995., 233-262.

\section{BERTELLI 2001}

Sergio Bertelli, The King's Body: Sacred Rituals of Power in Medieval and Early Modern Europe, University Park, Penn, 2001.

\section{BLÁHOVA 1997}

Marie Bláhova, „Die königliche Begräbniszeremonien im spätmittelalterlichen Böhmen“, 
u: Der Tod des Mächtigen (ur. Lothar Kolmer), Paderborn 1997., 89-112.

\section{BOULTON 1987}

D'Arcy Jonathan Dacre Boulton, The Knights of the Crown: The Monarchical Orders of Knighthood in Later Medieval Europe 1325-1520, Suffolk 1987.

\section{BOUREAU 2001}

Alain Boureau, Kantorowicz: Stories of a Historian, Baltimore 2001.

\section{BRKOVIĆ 1992}

Milko Brković, „Intitulacija i devocija u ispravama hrvatskih narodnih vladara", Radovi Zavoda za povijesne znanosti HAZU u Zadru 34, Zadar 1992., 75-97.

\section{CANNING 1996}

Joseph Canning, A History of Medieval Political Thought (300-1450), New York 1996.

\section{CANTOR 1991}

Norman F. Cantor, „The Nazi Twins: Percy Ernst Schramm and Ernst Hartwig Kantorowicz", u: Inventing the Middle Ages, New York 1991., 79-117.

\section{DURKHEIM 1972}

Emile Durkheim, O podeli društvenog rada, prev. Božidar Marković, Beograd 1972.

\section{ENGEL 2005}

Pál Engel, The Realm of St. Stephen: A History of Medieval Hungary 895-1526, prev. Andrew Ayton, London, New York 2005.

\section{FINK 1989}

Carol Fink, Marc Bloch: A Life in History, Cambridge 1989.

\section{FISKOVIĆ 2002}

Igor Fisković, Reljef kralja Petra Krešimira IV, Split 2002.

Istoimeni rad u „Reljef kralja Petra Krešimira IV.", Starohrvatska prosvjeta, III/28-29, 2001.2002., 7-360.

\section{FRIEDLANDER 2009}

Saul Friedlander, Nazi Germany and the Jews, Vol. 1, New York 2009.

\section{GALOVIĆ ET AL. 2008}

Tomislav Galović i Emir O. Filipović, „Prilog bibliografiji radova o heraldici (s posebnim osvrtom na Hrvatsku i Bosnu i Hercegovinu)", Arhivski vjesnik 51, Zagreb 2008., 161-226.

\section{GARIPZANOV 2008}

Ildar H. Garipzanov, The Symbolic Language of Royal Authority in the Carolingian World (c.751-877), Leiden 2008.

\section{GIEYSZTOR 1989}

Aleksander Gieysztor, „Gesture in the Coronation Ceremonies of Medieval Poland", u: Coronations. Medieval and Early Modern Monarchic Ritual (ur. János M. Bak), Berkeley 1989., 152-163.

\section{JOVANOVIĆ 2010}

Kosana Jovanović, Two Funerals and "Two Bodies" of King Richard II. A Study on the Idea of Kingship, Transference of Power and Political Theology, Saarbrücken 2010.

\section{JOVANOVIĆ 2013}

Kosana Jovanović, „Uloga efigija u pogrebnom ceremonijalu engleskih i francuskih kraljica te njihova povezanost s teorijom o dva kraljeva tijela“, Zbornik Odsjeka za povijesne Znanosti Zavoda za povijesne i društvene znanosti HAZU 31, Zagreb 2013., 21-36.

\section{JUSSEN 2009}

Bernhard Jussen, „The King's Two Bodies Today", Representations 106/1, Berkeley 2009., 102-117.

\section{KANTOROWICZ 1936}

Ernst Kantorowicz, Kaiser Friedrich der Zweite, 4. izdanje, Berlin 1936.

\section{KANTOROWICZ 1957}

Ernst Kantorowicz, The King's Two Bodies. A Study in Mediaeval Political Theology, Princeton 1957.

\section{KURELIĆ 2006}

Robert Kurelić, „Simboli statusa i moći: kneževski pečati Celjskih grofova" u: Med Srednjo Evropo in Sredozemljem - Vojetov zbornik (ur. Sašo Jerše, Darja Mihelič i Peter Štih), Ljubljana 2006., 61-78. 


\section{KURELIĆ 2006A}

Robert Kurelić, „Status Celjskih grofova kao kneževa Svetog Rimskog carstva", Zgodovinski časopis 60, vol. 1-2, Ljubljana 2006., 49-68.

\section{LEEUWEN 2006}

Jakoba van Leeuwen, "Introduction“, u: Symbolic Communication in Late Medieval Towns, Leuven 2006, vii-xix.

\section{LE GOFF 1977}

Jacques Le Goff, „Le rituel symbolique de la vassalité", u: Pour un autre Moyen âge, Pariz 1977., 349-419.

\section{MARASOVIĆ 2010}

Tomislav Marasović, „Splitska katedrala u ranome srednjem vijeku", Archaeologia Adriatica 4, Zadar 2010., 177-201.

\section{MCNAMARRA ET AL. 2007}

Patrick McNamarra i David Trumbull, An Evolutionary Psychology of Leader-follower Relations, New York 2007.

\section{MILLER 1997}

William Ian Miller, The Anatomy of Disgust, Cambridge MA 1997.

\section{PETNEKI 1997}

Áron Petneki, „Exequae Regis. Die Begräbniszeremonie des Königs Matthias Corvinus vor ihrem ungarischen Hintergrund", u: Der Tod des Mächtigen,(ur. Lothar Kolmer), Paderborn 1997., 113-135.

\section{SCHRAMM 1954-1978}

Percy Ernst Schramm, Herrschaftszeichen und Staatssymbolik: Beiträge zu ihrer Geschichte vom dritten bis zum sechzehnten Jahrhundert, vol 1-3, Stuttgart 1954.-1978.

\section{SCHRAMM 1968}

Percy Ernst Schramm, "'Mythos' des Königtums: Eine Einführung in das Problem: Monarchie in Europa", u: Kaiser, Könige und Päpste: Gesammelte Aufsätze zur Geschic[h]te des Mittelalters, vol 1, Stuttgart 1968., 68-78.

\section{THIMME 2006}

David Thimme, Percy Ernst Schramm und das Mittelalter, Göttingen 2006.

\section{TRACY ET AL. 2008}

Jessica L. Tracy, David Matsumoto, „The spontaneous expression of pride and shame: Evidence for biologically innate nonverbal displays", Proceedings of the National Academy of Sciences of the United States of America, 105/33, Washington 2008., 11655-11660.

\section{WARNER 1999}

David Warner, "Ideals and Actions in the Reign of Otto III", Journal of Medieval Studies 25, London 1999., 1-18.

\section{SAŽETAK}

Simboli i ceremonije neizostavan su čimbenik ljudskog društva i nalaze se posvuda u našem okruženju, od državnih i vjerskih simbola do ceremonija koje svjedoče o prijelazu iz jednog u drugi stadij života poput krštenja ili promocije. lako smo i danas pod velikim utjecajem ritualnog, u srednjovjekovnom su društvu nepisana i neverbalna komunikacija igrali vrlo značajnu ulogu.

To se ponajprije vidjelo u vladarskoj propagandi čija je legitimacija - milošću Božjom ovisila o vještoj vladavini jezikom simbola. Tri su povjesničara, Percy Ernst Schramm, Ernst Hartwig Kantorowicz i, u nešto manjoj mjeri Marc Bloch, udarili temelje izučavanju simbola i ceremonija u srednjemu vijeku. Schramm i Kantorowicz pripadaju njemačkoj historiografiji i obojica su imali bliske veze s nacizmom, iako je potonji zbog svojeg židovskog podrijetla u konačnici morao napustiti Njemačku te je svoje najznačajnije djelo The King's Two Bodies 
objavio u SAD-u. Bloch je objavio samo jedan, ali značajan rad na tu tematiku, i to o kraljevom iscjeliteljskom dodiru.

U Hrvatskoj se, dosad, simbolikom i ikonografijom najviše bavio povjesničar umjetnosti Igor Fisković, koji je komparativnim pristupom pokušao utvrditi identitet vladarskog lika na reljefu u krstionici splitske katedrale.

Proučavanje simbola nije samo sebi svrha. Na primjeru vladarskih pogreba u kasnom srednjem vijeku možemo, pomoću Kantorowiczeve teorije o dva kraljeva tijela - fizičkom i političkom - pratiti transfer vladarske propagande od Francuske do srednje i jugoistočne Europe, a preko Anžuvinske i Luksemburške dinastije, koje su vladale i Hrvatskim Kraljevstvom. Jednako tako, ambicije obitelji Celjski jasno se ocrtavaju upravo na planu simbolike koju su oni vješto koristili za izražavanje svojih pretenzija. Želja je autora da hrvatska historiografija u većoj mjeri koristi saznanja koja nam omogućuje proučavanje simbola i ceremonija za bolje razumijevanje problema iz hrvatske i regionalne povijesti.

\section{SUMMARY}

\section{Symbols and Ceremonies - Perspectives for the Study of Medieval History}

Symbols and ceremonies represent a vital factor in human society and they are found all around us, from state and religious symbols to rites of passage like baptism or graduation. Although we are heavily influenced by rituals today, the medieval society ascribed an important role to the unwritten and nonverbal communication.

This was primarily visible in the example of royal propaganda, as the king's legitimacy - by the grace of God - depended on his ability to master the language of symbols. Three historians, Percy Ernst Schramm, Ernst Hartwig Kantorowicz and, to a lesser extent, Marc Bloch, laid the foundation for the study of symbols and ceremonies in the Middle Ages. Schramm and Kantorowicz hail from German historiography and both had close ties with the Nazis, although the latter had to emigrate on account of his Jewish heritage and published his renowned book The King's Two Bodies in the US. Bloch published only one, but very influential book on this topic, about the healing touch of a king.

In Croatia the art historian Igor Fisković contributed the most to the study of symbols and iconography. His aim was to employ a comparative approach in order to determine the identity of the ruler on the relief in the baptistery of the cathedral of Split.

The study of symbols is not a self-contained discipline. On the example of royal funerals in the late Middle Ages we can, by applying Kantorowicz's theory of the king's two bodies - the physical and political - trace the transfer of royal propaganda from France to central and southeastern Europe. This was facilitated by the Angevin and Luxembourg dynasties, both of which ruled over the Croatian kingdom. Similarly, the ambitions of the counts of Cilli are clearly visible on the symbolic plane which they knew very well how to exploit in order to express their claims. It is the author's desire that Croatian historiography should, to a greater extent, employ the results of the study of symbols for a better understanding of problems in Croatian and regional history.

Keywords: symbols and ceremonies, P. E. Schramm, E. H. Kantorowicz, Marc Bloch, Croatian Middle Ages 